\section{Spatial Variation of Steryl Glucosides in Cycas micronesica Plants: Within- and Among-plant Sampling Procedures}

\author{
Thomas E. Marler ${ }^{1}$ \\ College of Natural and Applied Sciences, University of Guam, UOG Station, \\ Mangilao, Guam 96923
}

\author{
Vivian Lee and Christopher A. Shaw \\ Department of Ophthalmology, University of British Columbia, Vancouver, \\ $B C$, Canada \\ Additional index words. ALS-PDC, cycad, Guam, neurotoxins, sampling methods, \\ secondary compounds, steryl glucosides
}

\begin{abstract}
Amyotrophic lateral sclerosis-parkinsonism dementia complex (ALS-PDC) of the Western Pacific has been linked to the consumption of washed Cycas micronesica seed tissue. The search for a causal toxin in the seed tissue has generated decades of research, yet none of the published reports include an adequate description of sampling methods. We set out to design and conduct a study to serve as a model for future research. We used three populations of plants with similar recent plant life history, size, shade, seed load, and co-occurring species to determine intra- and interplant variation of four steryl glucoside variants. Variation was greatest among tissue types within seeds, intermediate among plants, and least among locations within plants. Results demonstrate the need of adhering to appropriate sampling protocols in cycad biochemistry research. Uses of appropriate sampling scheme and sample size are clearly required to avoid artifacts as this important area of research progresses.
\end{abstract}

Cycas micronesica K.D. Hill is endemic to Guam and nearby islands in the Western Pacific, and is defining of landscape-level physiognomy in many habitats in Guam. All cycads produce numerous secondary metabolites, many of which remain unidentified (e.g., Norstog and Nicholls, 1997). Six decades ago the correlation between exposure to neurotoxic metabolites in C. micronesica and the excessive incidence of neurological disease in Guam in the form of ALS-PDC was initially proposed for study in the medical research community (reviewed in Kurland, 1988; Kurland et al., 1994; Mabry, 2001). At no time has the description of an adequate field sampling protocol that adheres to plant science standards been included in the many research articles that have been published during the ensuing decades.

The considerable literature on the subject of intra- and interplant sampling variation is largely defined by research in commercial fruit production. Clearly, the procedures for estimating maturity of a commercial fruit crop must be accurate to market a saleable product. Similarly, maintaining strict adherence to methods that maximize accuracy is necessary in cycad ethnobotany or medical research. But

Received for publication 27 Dec. 2004. Accepted for publication 27 Apr. 2005. We thank J. Chung, C. Melder and N. Dongol for assistance. Support provided by USDA CSREES Special Grant in Tropical/ Subtropical Agricultural Research to TEM and U.S Army Medical and Materiel Command (DAMD1702-1-0678), NSERC Canada, and Scottish Rite Charitable Foundation of Canada to CAS.

${ }^{1}$ Corresponding author; e-mail tmarler@uog.edu. $\mathrm{sa}=$ sarcotesta, $\mathrm{sc}=$ sclerotesta sample size needed to obtain accurate results is not acceptable.

Our objectives were to delineate the relative intra- and interplant variation of four phytosterol and phytosterol glucoside compounds in seeds from C. micronesica plants for defining future research methods. We discuss these results in the context of past research which has ignored the need to define appropriate sampling protocols.

\section{Materials and Methods}

Plant neighborhood descriptions. We began examining cycad population dynamics in several habitats and throughout the urban landscape in Guam in 1997. Detailed phenology records were initiated for individuals in five contrasting habitats in June 2002. We focused on one of these plant communities for the present study to define the extent of intra- and interplant variation.

The study site is located on the west side of the island 0.65 to $0.75 \mathrm{~km}$ from the shoreline in the Andersen Air Force Base overlay of the Guam National Wildlife Refuge in Ritidian. The site gently descends from 135 to 105 $\mathrm{m}$, and the north edge of the site is about 1.2 $\mathrm{km}$ south of the northern point of the island $\left(13^{\circ} 39^{\prime} \mathrm{N}, 144^{\circ} 51^{\prime} \mathrm{E}\right)$. Annual rainfall of about $250 \mathrm{~cm}$ is seasonal, with precipitation exceeding evapotranspiration only from July through November(Young, 1988). The calcareous soils formed in slope alluvium, loess, and sediments overlying coralline limestone (Ritidian-Rock outcrop complex; clayey-skeletal, gibbsitic, nonacid, isohyperthermic Lithic Ustorthents) (Young, 1988).

Cycas micronesica plants are dominant understory plants in Guam's forests that are underlain by the Ritidian soils. This cycad has a conspicuous flushing growth habit where leaves or female megasporophylls develop in

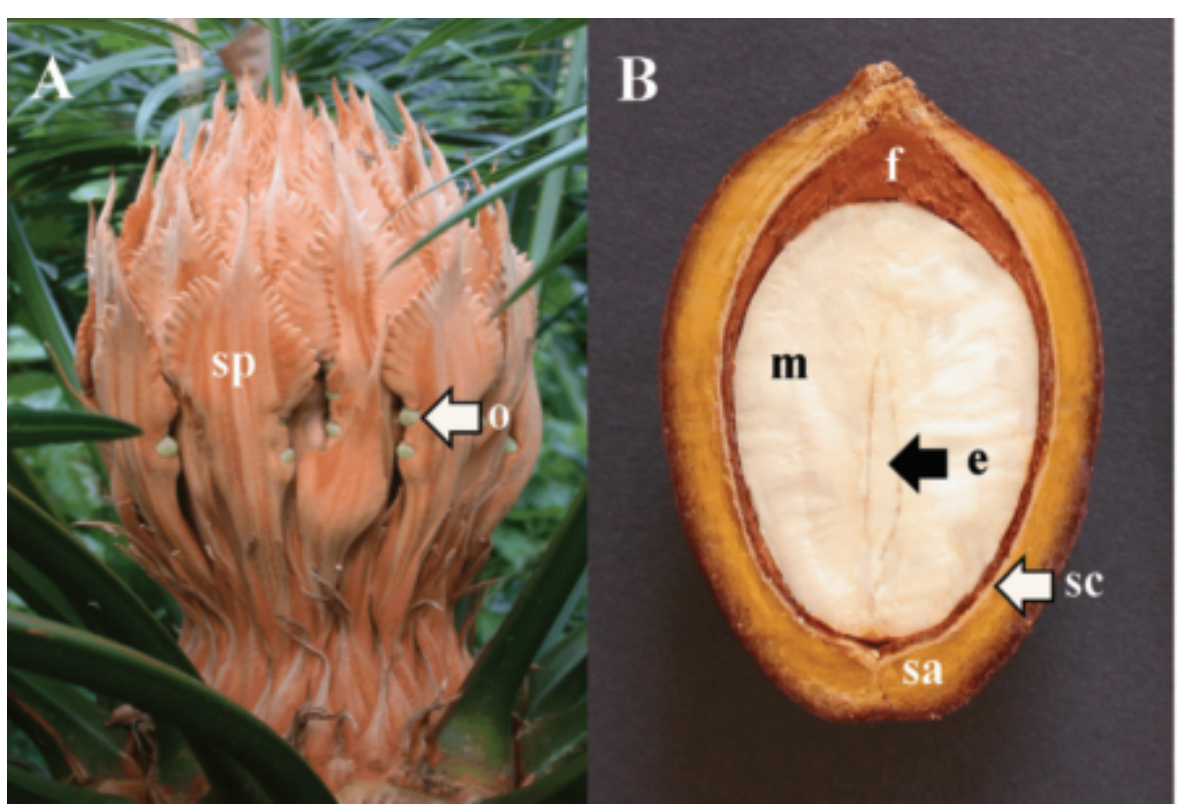

Fig. 1. Phenotype of female reproductive structures for Cycas micronesica. (A) Cohort of megasporophylls at 8 weeks following synchronized emergence from stem tip; $\mathrm{sp}=$ individual megasporophyll, $\mathrm{o}=$ naked ovule. (B) Cross-section of 20-month-old seed; $\mathrm{e}=$ embryo, $\mathrm{m}=$ megagametophyte, $\mathrm{f}=$ flotation layer, 
pulses (Fig. 1A). The production of a vegetative or reproductive growth flush occurs on individual plants in any month of the year in Guam. However, partially synchronized flushes of growth occur throughout the urban and forest populations. Recent synchronized flushing events in this study site occurred in January, April, June, and August 2003, and January 2004. Other endemic and indigenous species that define this plant community are varied. However, the list of understory species within a 2-m radius of $C$. micronesica plants and the list of canopy species that provide shade to C. micronesica plants are limited. In addition to close conspecific neighbors, the list of species that exist as close understory neighbors of cycad plants is dominated by the following genera: Aglaia, Cynometra, Guamia, Neisosperma, and Ochrosia. To a lesser extent, species represented by the following genera are also close neighbors: Eugenia, Hernandia, Morinda, and Tabernaemontana. The most common canopy plants providing shade and detritus to cycad plants in this habitat include indigenous or endemic species of Aglaia, Ficus, Hernandia, Neisosperma, Ochrosia, Pisonia, and Premna; and to a lesser extent Cordia, Cynometra, Guamia, Intsia, Tabernaemontana, and Tristiropsis. In addition, attenuation of sunlight by neighboring $C$. micronesica plants occurs.

We selected plants with consistent characteristics from the study site for each of the three experiments using the following criteria. We began with our field notes on the timing of all vegetative growth modules subsequent to the emergence date of the reproductive cohort bearing the sampled seeds. This provided a preliminary list of female plants with homogeneous phenology history and seed age. This list was further refined in the field by selecting individuals with similar stem height as a measure of relative plant size and forest canopy openness as an estimate of relative shade. Finally, we used total seed load and the list of close neighbors within $2 \mathrm{~m}$ of each individual as factors to refine the list for a third time. Cycad stem damage from wild pigs (Sus scrofa L.) and a beetle larvae (Dihammus marianarum Aurivillius) are common in this site. The influence of herbivory history on cycad chemistry is not known, thus we did not include any individuals exhibiting signs of herbivory from these two consumers. Each of these and other variables were quantified at the time seeds were sampled for each experiment in order to control background factors that have the potential to introduce sample biases.

Experiment 1. We selected 8 homogeneous individuals bearing seeds on synchronized megasporophyll cohorts that emerged in July 2002. Vegetative flush cohorts on these plants emerged in January and June 2003. Seeds were harvested on 17, 18, or 19 Dec. 2003.

Plant height was measured from stem base to the top of the cataphylls that protect the stem tip. This is considerably shorter than total plant height inclusive of leaves. Stem girth was measured as circumference at 1-m above the soil line. We selected this height because the stem girth of most individuals is fairly homogeneous above this height. The total number of seeds was counted. We documented canopy cover as hemispherical photographs using a Nikon Coolpix 995 fitted with a fisheye adapter. The camera was positioned at the horizontal plane located at the tip of the tallest leaf of each plant for each image. Percent visible sky on each image was determined digitally (Regent Instruments, Inc., Sainte-Foy, Quebec, Canada). Means for these quantified independent variables are presented in Table 1.

Close neighbors were represented by at least one individual for each genus listed above as the dominant neighbors and Morinda. These plants were under the influence of sunlight attenuation and litterfall inputs by every genus in the major list above, along with Guamia and Cynometra.

Sampling zone means were based on compass readings to define $\mathrm{N}, \mathrm{S}, \mathrm{E}, \mathrm{W}$ oriented lateral zones for each plant. Seeds were transported intact to the University of Guam, where each was separated into four tissue types (Fig. 1B). The exterior of each sarcotesta was peeled away, and this skin was one tissue category. The soft sarcotesta was scraped from the sclerotesta broken open to remove the megagametophyte as the third tissue category. Embryo tissue was included in this tissue category. The sclerotesta tissue was the fourth category, and any remnants of the flotation layer were included with sclerotesta.

Tissue samples were immediately placed in a freezer at $-40^{\circ} \mathrm{C}$ and held at this temperature until being lyophilized. Each sample consisted of a composite of tissue from two plants. The tissue was freeze-dried in preparation for HPLC analysis.

Experiment 2. This study was simplified to include only megagametophyte tissue in order to focus strictly on the influence of lateral sample zone on steryl glucosides. We increased the number of plants to 24 individuals for this purpose. We could not find this many homogeneous plants from our list of female plants with megasporophyll emergence dates in 2002. Thus, we selected 24 homogeneous individuals bearing seeds on simultaneous megasporophyll flushes that emerged in March 2003. Subsequent emergence of vegetative flushes on these plants occurred in August 2003.

Independent variables were measured as described above with one exception. To standardize the harvest date to one calendar date, we began measuring all independent variables on 6 Mar. 2004, and all seeds were harvested on 10 Mar. 2004 after these measurements as the second tissue category. Each seed was

were completed. Independent variables are reported in Table 1. Close neighbors were represented by at least one individual for each genus listed above as the dominant neighbors. These cycad plants were under the influence of sunlight attenuation and litterfall input by every genus in the major list above.

We focused on megagametophyte tissue in this second study, which is the portion of the seed that has been used to process flour for human consumption. Each sample zone was represented by 12 samples. Each sample consisted of tissue from two plants, for a total of 24 plants being represented in each sample zone mean. Tissue was frozen and lyophilized as described above.

Experiment 3. This study was simplified such that samples were a composite of all four sample zones used in Expts. 1 and 2. We did this to remove sample zone from the list of sources of variation in order to focus on the influence of seed tissue type on steryl glucosides. We increased the number of sampled plants to 15 individuals for this purpose. Homogeneous individuals bearing seeds on synchronized megasporophyll modules that emerged in Aug. 2002 were selected. Subsequent emergence of vegetative modules on these plants occurred in January and August 2003.

Independent variables were measured as in Expt. 2. We began measuring all independent variables on 10 Mar. 2004 and seeds were harvested on 12 Mar. 2004. The variation among observations for each of these independent variables was influenced by the hierarchy of our selection process (Table 1). In general, the numerical value for a standard error in proportion to the numerical value for its corresponding mean was less for canopy cover and stem height. These were the characteristics we used as our first level of screening from the potential list of individuals for each experiment. Stem circumference was also less variable than leaf number and seed number. This is a reflection of the probability that stem circumference scales more closely with stem height than does leaf number or seed production.

Close neighbors were represented by at least one individual for each genus listed above as the dominant neighbors. These plants were under the influence of sunlight attenuation and litterfall inputs by every genus in the major list above, along with Cynometra.

Tissue type was defined as megagametophyte, sclerotesta, and sarcotesta. Sarcotesta had been separated into the soft tissue and the exterior skin tissue in Expt. 1, but these two parts of the sarcotesta were not separated in Expt. 3. Each tissue type was represented by

Table 1. Characteristics of Cycas micronesica plants that were sampled in three experiments to determine the distribution of steryl glucoside subtypes among seed tissue types, among megasporophyll module locations, and among plants in habitat. Mean \pm SE.

\begin{tabular}{|c|c|c|c|}
\hline Characteristic & Expt. 1 & Expt. 2 & Expt. 3 \\
\hline Number of plants & 8 & 24 & 15 \\
\hline Percent canopy cover & $53 \pm 2$ & $59 \pm 2$ & $74 \pm 2$ \\
\hline Stem height $(\mathrm{cm})$ & $218 \pm 4$ & $356 \pm 5$ & $225 \pm 4$ \\
\hline Stem circumference ${ }^{\mathrm{z}}(\mathrm{cm})$ & $50 \pm 1$ & $72 \pm 2$ & $52 \pm 1$ \\
\hline Total leaf number & $52 \pm 2$ & $73 \pm 4$ & $64 \pm 4$ \\
\hline Total seed number & $26 \pm 2$ & $95 \pm 2$ & $33 \pm 2$ \\
\hline
\end{tabular}

${ }^{\mathrm{z}}$ At 1-m height. 
Table 2. Retention time (RT), relative retention time (RTT), and response factor of $\beta$-sitosterol $\beta$-D-glucoside (BSSG), stigmasterol $\beta$-D-glucoside (SG), $\beta$-sitosterol (BSS), and stigmasterol (SS) Standards.

\begin{tabular}{lccccccc}
\hline Compound & RT1 & RT2 & RT3 & mean & $\begin{array}{c}\text { SD } \\
\%\end{array}$ & $\begin{array}{c}\text { RRT } \\
\text { (to BSS) }\end{array}$ & Response \\
SG & 4.493 & 4.697 & 4.741 & 4.644 & 2.85 & 0.448 & 0.0001034 \\
BSSG & 4.982 & 5.116 & 5.146 & 5.081 & 1.72 & 0.490 & 0.0001432 \\
SS & 9.508 & 9.608 & 9.608 & 9.575 & 0.60 & 0.924 & 0.0000670 \\
BSS & 10.163 & 10.576 & 10.360 & 10.366 & 1.99 & 1.000 & 0.0001002 \\
\hline
\end{tabular}

Table 3. Concentration of phytosteryls and phytosteryl glucosides $\left(\mu \mathrm{g} \cdot \mathrm{g}^{-1}\right)$ within 4 sample zones of 17 month-old Cycas micronesica megasporophyll modules in Expt. 1 or 12-month-old megasporophyll modules in Expt. 2. Experiment 1 means based on a composite of 4 seed tissue categories. There were 30 samples per mean $( \pm \mathrm{SE})$, each sample comprised of tissue from 8 plants. Experiment 2 means based on 12 samples, each sample comprised of 1 seed from each of 2 plants. Thus, each mean is represented by tissue from 24 plants.

\begin{tabular}{lcccc}
\hline Sample zone & SG & BSSG & SS & BSS \\
\hline Experiment 1 & $469 \pm 104$ & $700 \pm 85$ & $205 \pm 25$ & $429 \pm 37$ \\
East & $244 \pm 47$ & $611 \pm 102$ & $166 \pm 25$ & $334 \pm 29$ \\
North & $310 \pm 56$ & $727 \pm 93$ & $162 \pm 20$ & $393 \pm 46$ \\
South & $504 \pm 93$ & $832 \pm 114$ & $205 \pm 34$ & $419 \pm 50$ \\
West & & & \\
Experiment 2 & $560 \pm 86$ & ND $^{z}$ & $132 \pm 36$ & $524 \pm 86$ \\
East & $553 \pm 58$ & ND & $199 \pm 40$ & $578 \pm 69$ \\
North & $496 \pm 75$ & ND & $163 \pm 24$ & $518 \pm 72$ \\
South & $638 \pm 71$ & ND & $177 \pm 21$ & $525 \pm 64$ \\
West & & &
\end{tabular}

${ }^{2} \mathrm{ND}=$ not determined in Expt. 2.

Table 4. Concentration of phytosteryls and phytosteryl glucosides $\left(\mu \mathrm{g} \cdot \mathrm{g}^{-1}\right)$ within four tissue categories of 17 month-old Cycas micronesica megasporophyll modules in Experiment 1 or 19-month-old megasporophyl modules in Experiment 3. Experiment 1 means based on a composite of 4 sampling zone categories. There were 30 samples per mean, each sample comprised of tissue from 8 plants. Experiment 3 means based on 5 replications per mean. Each replication was comprised of tissue from 12 seeds total, 4 seeds from each of 3 plants. Thus, each mean represented by tissue from 60 seeds total.

\begin{tabular}{lcccc}
\hline Tissue type & SG & BSSG & SS & BSS \\
\hline Experiment 1 & & & & \\
$\quad$ Megagametophyte & $141 \pm 17$ & $304 \pm 36$ & $117 \pm 8$ & $297 \pm 36$ \\
Sclerotesta & $839 \pm 122$ & $1340 \pm 116$ & $352 \pm 35$ & $551 \pm 56$ \\
$\quad$ Inner sarcotesta & $297 \pm 29$ & $749 \pm 48$ & $142 \pm 13$ & $410 \pm 29$ \\
$\quad$ Outer sarcotesta & $251 \pm 16$ & $478 \pm 42$ & $127 \pm 11$ & $317 \pm 21$ \\
Experiment 3 & & & $101 \pm 45$ & $286 \pm 123$ \\
$\quad$ Megagametophyte & $389 \pm 137$ & $52 \pm 51$ & $156 \pm 81$ & $381 \pm 146$ \\
$\quad$ Sclerotesta & $915 \pm 398$ & $150 \pm 150$ & $398 \pm 111$ & $664 \pm 138$ \\
Sarcotesta & $326 \pm 17$ & $412 \pm 114$ & \\
\hline
\end{tabular}

five samples. We collected four seeds from three plants for each of these five samples. The four seeds were obtained from the sample zones represented by north, south, east, and west orientations. Thus, each tissue type mean was represented by tissue from 60 seeds obtained from 15 plants. The tissue was frozen and lyophilized as described above.

HPLC analysis. Reversed-phase HPLC analysis of cycad tissues was carried out using an Agilent HP1050 HPLC in conjunction with AgilentChemStation Software VersionA.09.01. The following columns were used: Agilent ZORBAX Eclipse (reversed phase) XDB-C18 $\mathrm{P} / \mathrm{N}$ 993967-302 Solvent saver 5 micron, $3.0 \times$ $150 \mathrm{~mm}$; Phenomenex SYNERGI $4 \mu$ POLARRP 80 Angstrom P/N 5343-26, $3.0 \times 150$ mm; ZORBAXEclipse XDB-C8 guard column with guard column holder (P/N 820888-901), $2.1 \times$ $12.5 \mathrm{~mm}, 5$ micron (P/N 821125-926).

Our methods used a column temperature of $30^{\circ} \mathrm{C}$, and mobile phase composition was isocratic : acetonitrile : methanol (80:20), flow rate was $0.5 \mathrm{~mL} \cdot \mathrm{min}^{-1}$, detection wavelength was $205 \mathrm{~nm}$, run time was $35 \mathrm{~min}$, and Injection volume was $10 \mu \mathrm{L}$. The steryl glucoside variants we studied were $\beta$-sitosterol $\beta$-D-glucoside (BSSG), stigmasterol $\beta$-D-glucoside (SG), $\beta$-sitosterol (BSS), and to ensure solubility. The reconstituted extract was sonicated for $1 \mathrm{~min}$ in an ultrasonic bath followed by centrifugation and/or filtration to remove particulates before transferring to HPLC vials.

HPLC methods used $10 \mu \mathrm{L}$ each of the standards and $10 \mu \mathrm{L}$ each of sample extracts. These were injected into the HPLC system and separated in isocratic mode and UV detection at $205 \mathrm{~nm}$. Peaks were identified by individual retention time for each compound corresponding to the standard peaks. Standard steryls and / or steryl glucosides were injected with each sample run. The relative retention time and the peak response were calculated and used for identifying and quantifying the corresponding peaks in the chromatograms (Table 2).

\section{Results}

Intraplant variation. The magnitude of variation among sample zones for 17-monthold seeds differed for each steryl glucoside variant (Table 3). Variation was greatest for SG, with a 2-fold difference between the minimum and maximum sample zone means. Variation among sample zones was minimal for 12-month-old seeds (Table 3 ). There was a trend in Experiment 1 suggesting that east and west zones exhibited greater steryl glucoside concentration than did the North and South zones. However, these differences were not significant according to $\mathrm{F}$ test, and the trend did not persist in Expt. 2. Thus, within the context of this study no systematic trends occurred in regards to orientation of seeds within a megasporophyll module.

Intraseed variation. Seed tissue zones exerted a strong influence on steryl glucoside concentration (Table 4). The variation for 17month-old seeds in Experiment 1 was greatest for SG, with a 6-fold difference between megagametophyte and sclerotesta tissue. The variation for 19-month-old seeds in Expt. 3 was greatest for SS, with a 3.9-fold difference between megagametophyte and sarcotesta tissue. Although the magnitude of differences and the relative ranking among the tissues differed among the steryl glucoside variants and experiments, diploid sclerotesta and sarcotesta tissues exhibited greater concentrations than haploid megagametophyte tissue in every case.

Among-plant variation. We focused on megagametophyte tissue in Expt. 2 to determine general interplant variation within the study site in relation to interzone variation within plants. The mean for each of these samples representing interplant variation was calculated on a composite of 8 seeds ( 4 seeds from each of 2 plants). Variation among these samples was greatest for BSS, with a 3.7-fold difference between one sample with $923 \mu \mathrm{g} \cdot \mathrm{g}^{-1}$ and another sample with $252 \mu \mathrm{g} \cdot \mathrm{g}^{-1}$. Variation was least for SG, with a 2.36-fold difference between one sample with $825 \mu \mathrm{g} \cdot \mathrm{g}^{-1}$ and another sample with $350 \mu \mathrm{g} \cdot \mathrm{g}^{-1}$. These orders of magnitude are more than double those for interzone variation in Expt. 2, indicating interplant variation greatly exceeded intraplant variation. This interplant variation occurred despite the three-level refining process we 


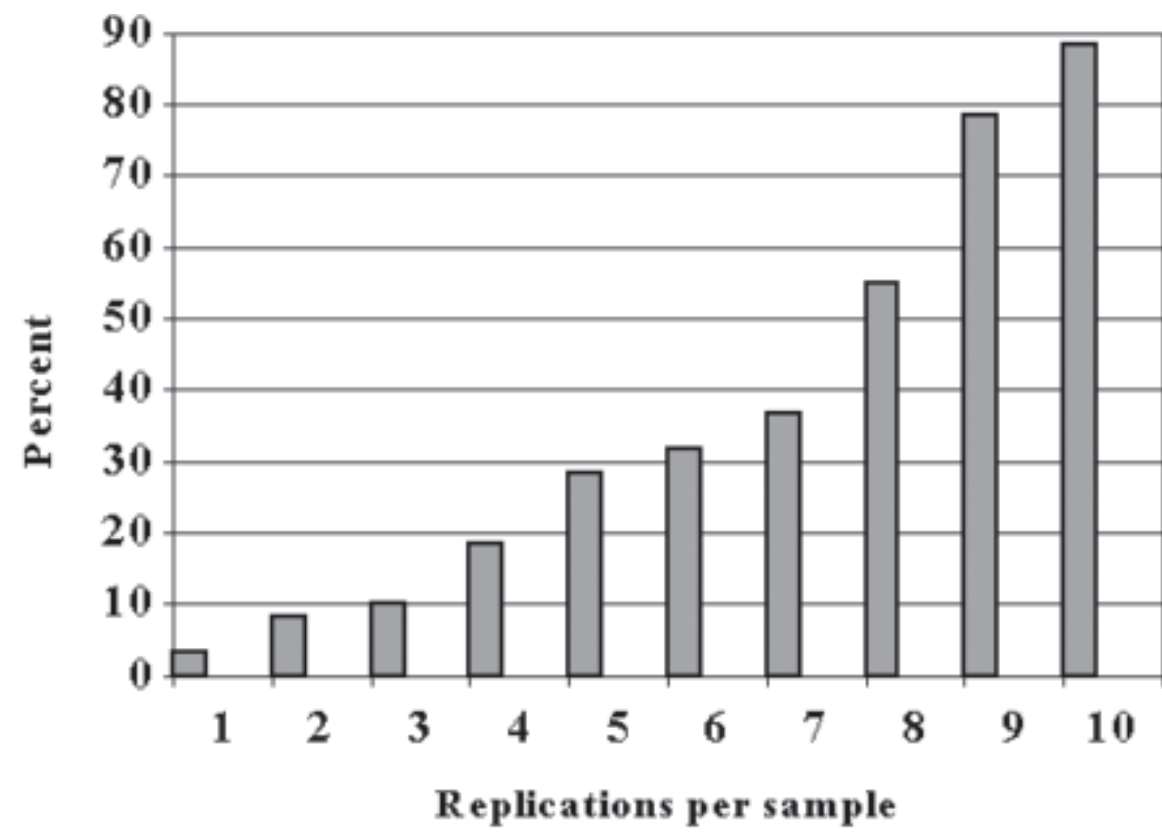

Fig. 2. The influence of replication number on the percentage of times the mean of each sample did not differ from the population mean based on 96 Cycas micronesica seeds. Population of observations was based on megagametophyte steryl glucoside concentrations in Expt. 2. Twenty repeated samples of 1 to 10 observations were obtained randomly.

used to standardize the population of plants for each experiment.

\section{Discussion}

Sampling scheme. The sources of variation we studied indicate partitioning of steryl glucosides among tissues within a plant exhibits greater variation than partitioning among lateral sampling zones within a megasporophyll module or among plants within a habitat. Furthermore, when considering secondary compounds in one tissue type as the characteristic of interest, interplant variation exceeded that of intraplant variation. Thus, for future research the population of plants within a community may be more accurately represented by a sampling scheme that harvests seeds from as many individuals as possible, rather than harvesting multiple samples from various zones within a fewer number of individuals in the sampling scheme. These results may not apply to cycad research in subtropical or temperate regions, since orientation of seeds within a megasporophyll module may exhibit greater influence on secondary metabolism by way of a more pronounced solar azimuth at these latitudes. For these regions, sampling from several sites within an individual plant may be required to accurately represent the individual.

An effort to define appropriate sampling schemes based on intrinsic interplant variation has been entirely ignored in past ALS-PDC research. No earlier article from this decadeslong area of research has quantified inherent sources of variation for the purpose of defining accurate sampling methods.

Sample size. Considering the number of observations we included and the background variables we controlled in this study, the level of variation we report reveals considerable intrinsic variation. Thus, future research must include adequate sample size to ensure sufficient accuracy and repeatability. However, conservation issues must also be included in determining sample size for research with this and other cycad species.

We used 96 seeds to determine population means for each steryl glucoside type in Expt. 2 , and suggest this number of seeds cannot be justified from a conservation perspective or in terms of costs associated with HPLC analysis. But the need for precision and accuracy of this research requires repeatability and a need to minimize deviations from the mean of repeated sampling procedures. Thus, we used the population of 48 observations from Expt. 2 to test repeatability and accuracy of 20 random samples for a range of sample sizes obtained from the parent population (Fig. 2). Random samples of 10 observations were able to predict the true population mean accurately with about $90 \%$ confidence. Thus, if field methods are designed to control background factors as extensively as in the present study and if sample collection methods adhere to our methods, we suggest a sample size of 10 as a minimum. This would be feasible from conservation as well as analytical cost perspectives.

Cox and Sacks (2002) proffer a hypothesis that includes consumption of BMAA from cycad sarcotesta by fruit bats, consumption of BMAA from fruit bats by humans, and neurodegeneration in human central nervous system regions thereafter. Data in Banack and Cox (2003) based on samples with 1, 2, or 3 replications have been used for crafting and propagating support of this hypothesis. Scientific standards should be honored in this important research field. Using a sample size of 1 does not allow for statistical validation, and failure to include statistical validation does not adhere to these standards. We have not included BMAA in our research to date because every study except one throughout the four decades since its identification (Vega and Bell, 1967) has universally failed to induce neurodegeneration phenotypes in animal models. That one exception occurred 20 years after its identification (Spencer et al., 1987), and that outcome has never been confirmed. Indeed, pure BMAA at high dosages equivalent to the quantity needed to validate the Cox and Sacks (2002) hypothesis have not elicited any behavioral or pathological outcomes in our lab (Cruz-Aguado et al., unpublished data) or in others (Perry et al., 1989).

The differences of BMAA concentration within and among $C$. micronesica plants are most likely as variable as those of the steryl glucosides we studied. Our results indicate a sample size of 1 would provide erroneous results $97 \%$ of the time, and a sample size of 3 would provide erroneous results $90 \%$ of the time (Fig. 2). However, since our methods included considerable control over background plant and habitat biases, accuracy would decline substantially below these percentages if methods were devoid of this control over sampling biases. Certainly, the merit of reported data based on 3 observations or less is dubious and the methods are indefensible.

The relative magnitude of deviations of sample means from the population mean is also critical for research precision. We obtained an estimate of precision by calculating the orders of magnitude of deviation of each sample mean depicted in Fig. 2 from the population mean based on 96 seeds. The deviation of greatest magnitude for any of the steryl glucosides estimated with samples of 10 observations was 1.34-fold for SS. Means of the deviations for all steryl glucoside subtypes exhibited a 1.07-fold difference between estimated means and the true population mean for samples based on 10 observations. In contrast, means from samples of 3 or less observations deviated from population means as much as 5.95-fold for BSS, 3.90-fold for SS, or 2.96-fold for SG.

These repeated applications of sampling from a population mean based on 96 seeds indicate that a mistake is expected $90 \%$ of the time when 3 or fewer observations are used, and the enormity of these mistakes is several orders of magnitude. A review of the decadeslong literature on cycad toxins indicates the need to define adequate sample size to ensure accuracy and precision has been universally ignored. Our results reveal that placing value in results based on sampling methods that ignore this need is not defensible. Similarly, sample bias can only be avoided by accounting for plant and habitat characteristics that are known to influence the response variable (see Marler et el., 2005) while defining the sampling scheme.

In conclusion, methods for studying plant toxins need to be standardized and must follow certain rigorous criteria to be valid in principle. Our results reveal some of these criteria include testing to determine appropriate sampling scheme and minimum sample size. 


\section{Literature Cited}

Banack, S.A. and P.A. Cox. 2003. Distribution of the neurotoxic nonprotein amino acid BMAA in Cycas micronesica. Bot. J. Linn. Soc. 143:165-168.

Cox, P.A. and O.W. Sacks. 2002. Cycad neurotoxins, consumption of flying foxes, and ALS-PDC disease in Guam. Neurology 58:956-959.

Hill, K.D and D.W. Stevenson. 2005. World list of cycads. 4 May 2005. http://plantnet.rbgsyd.gov. au/PlantNet/cycad/wlist.html.

Kurland, L.T. 1988. Amyotrophic lateral sclerosis and Parkinson's disease complex on Guam linked to an environmental toxin. Trends Neurosci. 11:51-53.

Kurland, L.T, K. Radhakrishnan, D.B. Williams, and
S.C. Waring. 1994. Amyotrophic lateral sclerosis-parkinsonism-dementia complex on Guam: epidemiological perspectives, p. 109-130. In: A Williams (ed.). Motor neuron disease. Chapman \& Hall, London.

Mabry, T.J. 2001. Selected topics from forty years of natural products research:Betalains to flavonoids, antiviral proteins, and neurotoxic nonprotein amino acids. J. Nat. Prod. 64:1596-1604.

Marler, T.E., V. Lee, and C.A. Shaw. 2005. Cycad toxins and neurological diseases in Guam: Defining theoretical and experimental standards for correlating human disease with environmental toxins. HortScience 40(6):1598-1606.

Norstog, K.J. and T.J. Nicholls. 1997. The biology of the cycads. Cornell Univ. Press, Ithaca, N.Y.
Perry, T.L., C. Bergeron, A.J. Biro, and S. Hansen. 1989. Beta-N-methyl-L-aminoalanine. Chronic oral administration is not neurotoxic to mice. J. Neurol. Sci. 94:173-180.

Spencer, P.S., P.B. Nunn, J. Hugon, A.C. Ludolph, S.M. Ross, D.N. Roy, and R.C. Robertson. 1967. Guam amyotrophic lateral sclerosis-parkinsonism-dementia linked to a plant excitant neurotoxin. Science 237:517-522.

Vega, A. and E.A. Bell. 1967. $\alpha$-Amino- $\beta$-methylaminopropionic acid, a new amino acid from seeds of Cycas circinalis. Phytochemistry 6:759-762.

Young, F.J. 1988. Soil survey of territory of Guam. U.S. Dept. Agr. Soil Cons. Serv. 